Published in final edited form as:

Cell Tissue Res. 2007 May ; 328(2): 421-430.

\title{
Distribution and characterization of nitric oxide synthase in the nervous system of Triatoma infestans (Insecta: Heteroptera)
}

\author{
Beatriz P. Settembrini, María F. Coronel, Susana Nowicki, Alan J. Nighorn, and Marcelo J. \\ Villar \\ B. P. Settembrini • M. F. Coronel • M. J. Villar Facultad de Ciencias Biomédicas, Universidad \\ Austral, Pte Perón 1500, B1629AHJ Pilar, Pcia de Buenos Aires, Argentina e-mail: \\ settembrini@macn.gov.ar
}

B. P. Settembrini Museo Argentino de Ciencias Naturales, C1405DJR Buenos Aires, Argentina

S. Nowicki Centro de Investigaciones Endocrinológicas-Conicet, C1425EFD Buenos Aires, Argentina

A. J. Nighom Arizona Research Laboratories, Division of Neurobiology, The University of Arizona, Tucson AZ 85721, USA

\begin{abstract}
The biochemical characterization of nitric oxide synthase (NOS) and its distribution in the central nervous system (CNS) were studied in the heteropteran bug Triatoma infestans. NOS-like immunoreactivity was found in the brain, subesophageal ganglion, and thoracic ganglia by using immunocytochemistry. In the protocerebrum, NOS-immunoreactive (IR) somata were detected in the anterior, lateral, and posterior soma rinds. In the optic lobe, numerous immunostained somata were observed at the level of the first optic chiasma, around the lobula, and in the proximal optic lobe. In the deutocerebrum, NOS-IR perikarya were mainly observed in the lateral soma rind, surrounding the sensory glomeruli, and a few cell bodies were seen in association with the antennal mechanosensory and motor neuropil. No immunostaining could be detected in the antennal nerve. The subesophageal and prothoracic ganglia contained scattered immunostained cell bodies. NOS-IR somata were present in all the neuromeres of the posterior ganglion. Western blotting showed that a universal NOS antiserum recognized a band at $134 \mathrm{kDa}$, in agreement with the expected molecular weight of the protein. Analysis of the kinetics of nitric oxide production revealed a fully active enzyme in tissue samples of the CNS of $T$. infestans.
\end{abstract}

\section{Keywords}

Brain; Subesophageal ganglion; Thoracic ganglia; NOS; NO production; (Insecta) Triatoma infestans

\section{Introduction}

The diffusible transmitter nitric oxide (NO) is generated by the activity of NO synthase (NOS) through the conversion of L-arginine to L-citrulline. In insects, NO signaling has been implicated in a wide variety of functions, including learning and memory, axonal guidance,

Correspondence to: Beatriz P. Settembrini.

This work was funded by the Facultad de Ciencias Biomédicas. Universidad Austral. A.J.N. is supported by the NIH-NIDCD (DC04292). Part of this work was performed at the Arizona Research Laboratories, Division of Neurobiology (Tucson, Arizon, USA) with the support of a Fulbright Research Award to B.P.S. 
and chemosensory, mechanosensory and visual processing (Davies 2000; Bicker 2001). Distribution studies performed with NADPH diaphorase histochemistry and immunocytochemistry have revealed that some staining patterns are conserved in both holometabolous and hemimetabolous insects. In this regard, NOS expression has been detected in cell bodies and neurites of the chemosensory system in all the insect species studied so far. On the other hand, variability in staining among species of both groups of insects has been reported in the antennal olfactory receptors, the optic lobe, and the mushroom body. This information suggests that certain patterns of NOS expression are a characteristic feature of a group of insects or can only be related to a given environmental or behavioural condition of the insect lifestyle.

With regard to the insect chemosensory system, NOS expression has been detected only in the antennal lobe or in both the antenna and the antennal lobe (Müller 1997). Furthermore, a role in modulation of communication between olfactory receptors and higher-order processing elements has been postulated for NO (Nighorn et al. 1998). Highly sensitive immunocytochemistry protocols (Settembrini and Villar 2004) might be useful to determine whether these diverse distributions of NOS are linked to different chemosensory modalities. The recent availability of antibodies generated against a peptide sequence conserved in all known insect NOS (Regulski and Tully 1995; Yuda et al. 1996; Nighorn et al. 1998; Luckhart and Rosenberg 1999; Imamura et al. 2002) and the use of secondary reagents that enhance the detection of the antigen-antibody reaction provide a sensitive and specific tool for the tissue localization of this enzyme. The highly specific immunolocalization of the enzyme has been shown to match sites of in-situ hybridization for NOS mRNA but lacks the limitations inherent in the latter technique (Hsu et al. 1981; Shu et al. 1988; Gibson and Nighorn 2000).

Most triatomine species (Heteroptera: Reduvvidae, Tri-atominae) are domestic vectors of Chagas' disease, which affects 16-18 million people in Latin America. It is estimated that about $25 \%$ of the inhabitants of this region are at risk of contracting the infection (WHO 2002).

Triatoma infestans is the most important vector of this endemic disease in Southern Cone countries. These insects rely on chemosensory cues to locate warm-blooded food sources (Taneja and Guerrin 1995;Guerenstein and Guerin 2001), but the anatomical location of the specific centers involved in either the control or modulation of this behavior is still unknown. Because of the role of NO signaling in the development (Gibson and Nighorn 2000) and function of the insect antennal lobe, a determination of the distribution of NOS in the brain and ganglia of $T$. infestans by immunocytochemistry, together with the analysis of the biochemical parameters of this enzyme, may provide insights into its function.

In the present study, we describe the distribution pattern of NOS in the central nervous system (CNS) of T. infestans and present data for this species concerning the molecular weight, catalytic activity, and NO production of this enzyme. A preliminary report of these investigations has been published in abstract form (Settembrini et al. 2005).

\section{Materials and methods}

\section{Insects}

Adult male Triatoma infestans, free of Trypanosoma cruzi and Blastocrithidia triatomae, were used in this study. The insects were derived from stocks provided by the Center for the Control of Chagas' disease (Santa María, Córdoba, Argentina) and were maintained under controlled conditions of light, temperature, and relative humidity (Settembrini 1984). 


\section{Dissection and fixation}

Insects $(n=45)$ were processed for immunocytochemistry 2 weeks after feeding. The brain and ganglia were dissected out and fixed overnight in a mixture of $4 \%$ paraformaldehyde and $0.4 \%$ picric acid in $0.16 \mathrm{M}$ sodium phosphate buffer $(\mathrm{PB}, \mathrm{pH} 6.9)$ at $4^{\circ} \mathrm{C}$. Subsequently, the samples were rinsed in $0.01 \mathrm{M}$ phosphate-buffered saline $(0.13 \mathrm{M} \mathrm{NaCl}$ in $\mathrm{PB}$ at $\mathrm{pH} 7.4 ; \mathrm{PBS})$ and transferred to PBS containing $15 \%$ sucrose, $0.02 \%$ bacitracin (Sigma, St. Louis, Mo., USA), and $0.01 \%$ sodium azide (Merck, Darmstadt, Germany) for at least $48 \mathrm{~h}$, at $4^{\circ} \mathrm{C}$ (Settembrini and Villar 1999).

\section{Immunocytochemistry}

Whole-mount preparations ( $n=6$ insects) of the brain and subesophageal and thoracic ganglia were transferred to PBS containing 1\% Triton X-100 (PBST) for at least $48 \mathrm{~h}$. They were then immersed in PBS containing 10\% normal donkey serum for $1 \mathrm{~h}$ in order to reduce non-specific binding. The same solution was also used to dilute the primary and secondary antisera. The samples were incubated for $24 \mathrm{~h}$ at $4^{\circ} \mathrm{C}$ with polyclonal universal NOS antibodies (uNOS, Oncogene Research Products, Cambridge, Mass., USA; 1:200) raised in rabbits and directed against the sequence KRYHEDIFG. Samples were subsequently incubated with fluorescein isothiocyanate (FITC)-conjugated goat anti-rabbit (1:80, Jackson ImmunoResearch Labs, Pa., USA) secondary antibodies for $30 \mathrm{~min}$ at $37^{\circ} \mathrm{C}$. Brains and ganglia were mounted in $80 \%$ glycerol and observed under a Nikon PCM 2000 laser-scanning confocal microscope, mounted on an E800 microscope equipped with green $\mathrm{He} / \mathrm{Ne}(543 \mathrm{~nm})$, red $\mathrm{He} / \mathrm{Ne}(633 \mathrm{~nm})$, and argon $(488 \mathrm{~nm})$ lasers and the appropriate filters. Stacks of digitized images were merged and processed by using Simple PCI 3.2 (Compix, Cranberry Township, Pa., USA). If necessary, the digitized images were modified but only to enhance contrast (Adobe Photoshop, Adobe Systems, San José, Calif., USA). Serial horizontal sections from another group of insects $(n=9)$ were processed for immunofluorescence as stated above. The sections were observed and photographed in a Nikon E800 microscope equipped with appropriate filters.

Serial horizontal cryostat sections (Microm, Waldorf, Germany) from 30 insects were processed according to the avidin-biotin immunoperoxidase protocol (ABC; Hsu et al. 1981). The sections $(18 \mu \mathrm{m})$ were incubated overnight with uNOS antiserum diluted 1:300, rinsed in PBS, incubated at room temperature (RT) for $30 \mathrm{~min}$ in biotinylated goat anti-rabbit secondary antibodies (1:100; Vector Laboratories, Burlingame, Calif., USA), rinsed again in PBS, and further incubated for $1 \mathrm{~h}$ in the ABC reagent (Vectastain Elite kit, Vector Laboratories).

Peroxidase activity was revealed by reaction with 3,3'-diaminobenzidine tetrahydrochloride (Sigma) by using glucose oxidase (Sigma) and nickel salts for the enhancement of the reaction product (Shu et al. 1988). The sections were examined with a Nikon E800 microscope and photographed by using a Nikon DN100 digital-net camera.

Control experiments were performed by incubating the sections without primary antiserum. No immunostaining was seen.

\section{Electrophoresis and Western blots}

The brain with the subesophageal ganglion (SOG) and the thoracic ganglia was quickly dissected out of the cuticle and placed in a Petri dish on a few droplets of ice-cold $0.01 \mathrm{M}$ PBS containing the following protease inhibitors (PBS+I) with their final concentrations $(\mu \mathrm{g} / \mathrm{ml})$ : antipain dihydro-chloride (60), bestatin (10), chymostatin (20), E-64 (60), leupeptin (10), pepstatin (10), phosphoramidon (60), pefastoc-SC (400), EDTA (200), and aprotinin (10), all from Roche Diagnostics Scandinavia (Bronma, Sweden). Dissection proceeded with the tissues constantly being bathed in PBS+I until the brain and ganglia were separated from the surrounding tissues. Groups of 10 brains and ganglia were stored in $100 \mu \mathrm{PBS}+\mathrm{I}$ at $-70^{\circ} \mathrm{C}$ until assayed. Tissues were sonicated, and the protein concentration of the homogenate was 
determined (Bradford 1976). Protein samples ( $25 \mu \mathrm{g}$ ) from the nervous tissue were solubilized in $0.75 \%$ TRIS-HCl buffer, containing $2 \%$ sodium dodecyl sulfate (SDS), $40 \%$ glycerol, and $10 \% \beta$-mercaptoethanol, $\mathrm{pH} 6.8$, and loaded in each well for separation by SDS-

polyacrylamide gel electrophoresis ( $8 \%$ gels) at $150 \mathrm{~V}$ for $1.5 \mathrm{~h}$ (Laemmli 1970). Proteins were transferred to a polyvinylidene difluoride membrane (Amersham-Pharmacia Biotech, Uppsala, Sweden) at $100 \mathrm{~V}$ for $1 \mathrm{~h}$. Membranes were blocked in 5\% non-fat dry milk in PBS for $1 \mathrm{~h}$ at room temperature with gentle shaking, incubated with uNOS antiserum at 1:500 dilution for $1 \mathrm{~h}$, washed, and incubated with peroxidase-conjugated anti-rabbit antibodies (1:10,000; Amersham-Pharmacia Biotech). Immunoreactivity was detected by using the ECL-Plus kit (Amersham-Pharmacia Biotech).

\section{NOS activity}

Brains and ganglia were rapidly dissected out from surrounding tissues and washed in a $10 \%$ solution of protease inhibitors in sterile saline $(0.13 \mathrm{M} \mathrm{NaCl})$. Samples from seven insects were pooled and homogenized in $20 \mathrm{mM}$ TRIS- $\mathrm{HCl}$ (pH 7.4) with $0.32 \mathrm{M}$ sucrose, $2 \mathrm{mM}$ EDTA, 2 $\mathrm{mM}$ dithiothreitole (DTT), and 10\% protease inhibitors (protease inhibitor cocktail; Sigma). The homogenates were centrifuged at 2,000 $\mathrm{rpm}$ for $10 \mathrm{~min}$ at $4^{\circ} \mathrm{C}$, and the supernatants were stored at $-30^{\circ} \mathrm{C}$ until used.

NOS activity was determined in the homogenates by following, spectrophotometrically, the oxidation of oxyhemoglobin to methemoglobin (Feelisch and Noack 1987). Briefly, each sample (1 mg protein $/ \mathrm{ml})$ was incubated at $37^{\circ} \mathrm{C}$ with a reaction medium containing $50 \mathrm{mM}$ phosphate buffer $\mathrm{pH} 7.0,1 \mathrm{mM} \mathrm{CaCl}_{2}, 1 \mathrm{mM} \mathrm{L}$-arginine, $100 \mu \mathrm{M} \mathrm{NADPH}, 10 \mu \mathrm{M}$ DTT, 0.1 $\mu \mathrm{M}$ catalase, $4 \mu \mathrm{M}$ superoxide dismutase (SOD), and $5 \mu \mathrm{M}$ oxyhemoglobin. All the reagents were purchased from Sigma. Catalase and SOD were added to prevent the interference of hydrogen peroxide and superoxide, respectively. The formation of methemoglobin following the oxidation of oxyhemoglobin by NO was followed at $401 \mathrm{~nm}\left(\varepsilon=38 \mathrm{mM}^{-1} \mathrm{~cm}^{-1}\right)$, and the increase in absorbance was expressed as nanomoles of $\mathrm{NO}$ produced per minute per milligram of protein. $\mathrm{N}^{\mathrm{G}}$-methyl-L-arginine ( $1 \mathrm{mM}$; L-NMMA, Sigma) was added in control experiments to confirm that hemoglobin oxidation was occurring because of NO production only.

\section{NO production}

Brains and ganglia were dissected out and stored as stated above. NO production was evaluated by measuring its stable degradation products, nitrite and nitrate (NOx), by using an NO Analyser 280 (Sievers Instruments, Boulder, Colo., USA). NOx present in the samples was reduced by $\mathrm{VCl}_{3}$ (Aldich, St. Louis, Mo., USA) in $\mathrm{HCl}$ at $90^{\circ} \mathrm{C}$ to form $\mathrm{NO}$ (Braman and Hendrix 1989). The NO product reacted with ozone in a gas-phase chemiluminescent reaction with the generation of $\mathrm{NO}_{2}$ whose emissions in the red and near-infrared region of the spectrum were detected by a photo-multiplier tube. The analyzer was calibrated with solutions (1-100 $\mu \mathrm{M})$ of $\mathrm{NaNO}_{3}$. Each tested sample was the result of pooling the brains and ganglia of eight insects.

\section{Expression of data and statistical analysis}

Protein concentration was determined according to Bradford (1976). Both NOx levels and NOS activity were normalized to the protein content of each sample and expressed as nanomoles of NOx per milligram of protein and nanomoles of NO produced per minute per milligram of protein, respectively. Data were analyzed with GraphPad Prism software. The ANOVA test and Newman-Keuls multiple comparison test were used. Results are expressed as means \pm SEM. Results were classified as non-significant (ns; $P>0.05$ ) or statistically significant $(* 0.05>P>0.01, * * 0.01>P>0.001, * * * P<0.001)$. 


\section{Results}

\section{Distribution of NOS-like immunoreactivity}

Brain-The brain, composed of the protocerebrum (PC), deutocerebrum (DC), and tritocerebrum (TC), is located within the head capsule, together with the SOG. Because of the massive development of the pharyngeal muscles, the DC and TC lie ventral to the dome-shaped protocerebral lobes. Thus, after removal of the dorsal cuticle of the head, only the protocerebral hemispheres and the posterior third of the SOG can be observed.

NOS-immunoreactive cell bodies-The distribution pattern of NOS-immunoreactive (IR) somata and fibers of the PC and optic lobes (OL) is portrayed in Fig. 1a. Immunoreaction product was mostly distributed evenly within the cytoplasm of the cell body; however, in a few positive somata, a granular deposit was observed.

Protocerebral NOS-immunoreactive (IR) cell bodies were also observed in the anterior, lateral, and posterior soma rinds, either as single elements or forming cell-body clusters (Fig. 2a). A cluster of medium-sized perikarya $(11-15 \mu \mathrm{m})$ showing immunoreactive granules was found close to the mushroom-body calyces. Other immunostained somata were observed around the anterior PC neuropil, at the anterolateral edge (Fig. 2a), and at the boundary of the PC with the OL (Fig. 2c). The lateral cell-body cortex housed single positive somata (Fig. 2c) and a lateromedial cluster of about ten medium-sized perikarya (Fig. 2a). A group of four small somata $(6-10 \mu \mathrm{m})$ was located near the posterolateral edge, whereas scattered immunolabeled perikarya of various sizes were seen in the posterior soma rind (Fig. 2d).

In the OL, numerous immunostained somata were observed between the neuropils of the outer medulla and the lamina ganglionaris (Fig. 2b). In these small fusiform cell bodies (6-10 $\mu \mathrm{m}$ ), NOS-like immunoreactivity (LI) formed a thin rim below the cell membrane. Moreover, NOSIR perikarya were found in the medial layer at the level of the lobula and in both the medial and lateral layers of the proximal OL (Fig. 1a).

In the DC (Fig. 1b, upper part), the highest number of immunolabeled somata was observed around the sensory glomeruli (Fig. 3a,b). Numerous small perikarya $(6-10 \mu \mathrm{m})$ were seen in the lateral cell-body cortex (Fig. 3b), whereas only a few could be found in the medial and anterior soma rinds. Other deutocerebral NOS-IR perikarya were detected at the anterolateral edge and at the level of the posterior glomeruli (Fig. 1b). Immunopositive cell bodies of the antennal-mechanosensory and motor center were located in the lateral soma rind (Fig. 1b).

NOS-IR fibers-The distribution of NOS-LI in the neuropils of the PC and OL is depicted in Fig. 1a. Patches of NOS-IR fibers were observed in the anterior PC neuropil. Immunostained fibers were seen traversing the median furrow between the PC lobes (Fig. 2a,d). The calyces and the $\alpha$ - and $\beta$-lobes of the mushroom bodies were unstained (Fig. 2c). In the central body, the peripheral layers (Fig. 2d) showed a higher level of NOS-LI than the central zone of this neuropil.

In the OL, NOS-IR fibers were observed in the lobula and in the outer and serpentine layers of the medulla (Fig. 2b). NOS-IR processes of the lamina ganglionaris showed a columnar array. A fiber tract formed by several NOS-IR neurites was seen running from the outer medulla to the anterior PC neuropil.

No immunostaining could be detected in the antennal nerve (Figs. 3a,b), although a high density of immunoreactive processes was observed in the sensory glomeruli (Fig. 3b) which surrounded an unstained central core. The neuropil of the antennal-mechanosensory and motor 
center harbored a few positive neurites (Fig. 3b). NOS-LI was also evident in fibers around the esophageal foramen (Fig. 3c).

Subesophageal ganglion-Two cell body clusters were observed in the anterior SOG (Fig. $1 \mathrm{~b}$, lower part), one of them was located in the anterior soma rind in a medial position, whereas the other, formed by five large $(16-20 \mu \mathrm{m})$ cell bodies, was located at the level of the mandibular neuromere (Fig. 3c). Small somata were observed in the posterior SOG close to the origin of the cephalic connectives.

The neuropil of SOG neuromeres displayed a moderate density of NOS-IR processes. Bilateral medial immunolabeled fibers and commissures were also present.

Thoracic ganglia-Scattered NOS-IR perikarya were found in the prothoracic ganglion. They were located near the anterior and posterior connectives and close to the root of prothoracic nerve I (Fig. 1c). NOS-IR somata were present in each of the posterior ganglion neuromeres (Fig. 1c). Cell-body clusters of the abdominal neuromeres (Fig. 3d) contained a higher number of positive perikarya than those of the mesothoracic and metathoracic neuromeres.

Thoracic ganglia showed a moderate density of NOS-IR fibers, and beaded neurites were seen running close to the midline of both ganglia. Blebby immunostained fibers could be detected in abdominal nerves IV and V, and some tiny fibers were observed at the root of mesothoracic nerve III.

\section{Western blotting}

In $T$. infestans nervous tissue samples, uNOS antibodies detected a band corresponding to a molecular weight calculated as $134 \mathrm{kDa}$. The position of this band had the expected size of $132 \mathrm{kDa}$. Other bands were also detected at 90 and $77 \mathrm{kDa}$ (Fig. 4).

\section{NOS activity and NO production}

Figure 5 shows the kinetics of NO production by samples from the nervous tissue of $T$. infestans. NOS activity was determined in seven brain homogenates from control samples, yielding a mean value of $7.53 \pm 0.85 \mathrm{nmol}$ NO produced per minute per milligram protein. The addition of $1 \mathrm{mM}$ L-NMMA to the reaction mixture inhibited the rate of hemoglobin oxidation by $90 \%$, validating the specificity of the reaction.

The concentration of the oxidation products of NO, nitrite, and nitrate was determined in brain homogenates, yielding a mean value of $6.24 \pm 0.35 \mathrm{nmol} / \mathrm{mg}$ protein $(n=3)$.

\section{Discussion}

\section{Distribution of NOS-LI}

Using highly sensitive immunocytochemistry, we have shown the widespread distribution of NOS-LI in the brain and ganglia of T. infestans. The high sensitivity of this protocol has allowed the detection of numerous somata and intensely stained fibers with no unspecific immunostaining of cell bodies or neurites. This methodology has also improved the visualization of NOS-LI in cell-body clusters and faintly stained neuropils (Villar et al. 1994). The increase in sensitivity has been achieved by using uNOS antibodies together with the $\mathrm{ABC}$ reagent and with nickel salts for the intensification of the reaction product (Hsu et al. 1981; Shu et al. 1988). As previously stated, the uNOS antiserum is directed against the conserved epitope KRYHEDIFG. This amino-acid sequence is present in NOS from the salivary glands of Rhodnius prolixus, a species closely related to T. infestans. However, as this 
epitope corresponds to the NADPH-binding domain of NOS, the possibility of cross-reaction with other enzymes that use NADPH as a cofactor cannot be totally disregarded.

Of considerable interest is the finding of NOS-LI in the OL of $T$. infestans. NOS-LI has been found in first-order and higher integration neuropils. The extensive distribution of the immunolabeling suggests that NO plays an important function in visual processing in $T$. infestans. Eleven groups of somata have been recognized in the OL of Schistocerca gregaria by NADPH-diaphorase histochemistry (Elphick et al. 1996). The OL in T. infestans also contains groups of NOS-IR somata, although fewer in number, located close to the first and second chiasmata and in the proximal OL, thus matching the description reported for the locust. Several lines of research indicate that NO acts as a retrograde messenger from monopolar lamina cells to compound eye photoreceptors; this system might operate during the adaptation to darkness (Bicker 2001). In this context, the expression of soluble guanylyl cyclase, the best characterized target of NO, has been detected in the photoreceptors and retina of insects (Shah and Hyde 1995; Elphick and Jones 1998), and NO induces cyclic GMP immunoreactivity in the locust retina (Bicker and Schmachtenberg 1997). Furthermore, both molecules have been suggested to be involved in the movements of the pigment granules (Stürmer et al. 1995). T. infestans is a nocturnal species with apposition-type compound eyes. Its visual system is relevant in terms of allowing these bugs to find shelter, to escape from predators, and to gain access to a food source or to a conspecific. The locomotor activity of these insects shows a circadian rhythm, beginning shortly after dusk and ending at dawn (Settembrini 1984). Pigment movements within pigment and retinula cells have been observed in response to rhythmic changes of the dark-light cycle (Reisenman et al. 2002). NO released from the immunostained somata close to the first optic chiasma might diffuse through the lamina ganglionaris neuropil and thus modify the sensitivity of the photoreceptors acting through the migration of pigments. Other NO-releasing elements of the OL might either activate or modulate functions within the different steps of visual information processing.

A conserved role for NO in olfactory processing has been postulated, as NOS-LI and NADPHdiaphorase expression have been detected in chemosensory neuropils from invertebrates to higher vertebrates (Müller 1997). Differences in the labeling patterns of these enzymes have been reported in insect chemoreceptors. In T. infestans, specific antennal sensilla are responsible for the perception of host chemosensory signals (Guerenstein and Guerin 2001). In agreement with a previous report of the NADPH-diaphorase assay in S. gregaria (Bicker and Hähnlein 1995), NOS-LI is detected neither in the antennal chemoreceptors nor in the antennal nerves of $T$. infestans. Therefore, NO is unlikely to act as a messenger in chemosensory perception in this heteropteran insect. NOS-LI in the sensory deutocerebral glomeruli of these bugs derives mainly from NOS-IR somata of the lateral cell-body layer, which houses local interneurons and projection neurons. uNOS antiserum consistently labels the sensory glomeruli; however, regionalization in the immunostaining pattern within the glomeruli has not been observed. Thus, we have not been able to determine whether NOS-IR somata surrounding the glomeruli are projection neurons or local interneurons. Since no projections have been detected outside the glomeruli, we can hypothesize that NO release by these somata exerts a local action in the integration of sensory signals. The finding of NOS-LI in the antennal-mechanosensory and motor center of this triatomine bug is novel, as it has previously only been reported in $S$. gregaria (Kurylas et al. 2005). In T. infestans, this immunolabeling might originate from positive somata surrounding this neuropil, as antennal afferents show no immunoreactivity. Co-expression of NOS-LI with other messenger molecules has been reported for the olfactory and visual systems (Villar et al. 1994; Seidel and Bicker 1997). The possibility of co-release and interaction of NO with other neurotrasmitters or neuromodulators may be a relevant issue for future studies aimed at developing new drugs to combat triatomine vectors. 
Several protocerebral neuropils display NOS-LI. A fine-stippled immunoreaction product has been observed at the lateral margin of the stalk, whereas other neuropils of the mushroom body remain unstained. This immunolabeling pattern probably originates from extrinsic elements, as Kenyon cell bodies and the calyces are unstained. The central body, particularly its peripheral layers, exhibits heavy immunostaining. Recent studies in the grasshopper Chorthippus biguttulus have shown NADPH-diaphorase staining in neurons, which supply the peripheral layer of the upper division of the central body. Furthermore, activation of the NO/cGMP pathway has been able to inhibit sound production provoked by stimulation of muscarinic receptors in the central complex (Wenzel et al. 2005). T. infestans possesses a well-developed stridulatory organ (Di Luciano 1981), and sound production has been related to mating behavior (Manrique and Lazzari 1994). Although the source of NOS-LI in the central body has not yet been identified, and since the function of this neuropil is unknown in T. infestans, NO release in this neuropil might be related to the control of sound production.

Compared with the brain, the subesophageal and thoracic ganglia contain fewer NOS-IR perikarya. Immunostaining is also present in neuropils and intersegmental and commissural fibers. The SOG of $T$. infestans sends branches to several structures of the feeding apparatus, including the salivary glands (Insausti 1994). Moreover, the mandibular and maxillary neuropils are the target of fibers from the sensilla chaetica of the anterior part of the head capsule. Cobalt filling has also revealed that the neuromeres of the prothoracic and posterior ganglia receive afferents from cephalic and abdominal sensilla chaetica (Insausti and Lazzari 2000). Distribution studies performed by NADPH-diaphorase staining of the ventral nerve cord of $S$. gregaria suggest a role for NO in the processing of mechanosensory information (Ott and Burrows 1998). As previously suggested for this orthopteroid species, NO might also be involved in the processing of information from mechanoreceptors of the body surface and the subsequent generation of appropriate behavioural responses in T. infestans. Our finding of immunostained neurites in the abdominal nerves and the root of mesothoracic nerve III suggests that NO can be synthesized by cells other than interneurons.

\section{Molecular and biochemical properties of NOS in T. infestans}

Western blotting has revealed the presence of a stained band at $134 \mathrm{kDa}$ in the nervous tissue of the CNS in T. infestans; this is in good agreement with the molecular weight of $132 \mathrm{kDa}$ reported for NOS of the salivary gland of $R$. prolixus (Yuda et al. 1996). These results are also in agreement with previous reports in non-triatomine species (Elphick et al. 1995; Nighorn et al. 1998). The presence of other bands of lower molecular weights between 90 and $51.7 \mathrm{kDa}$ is also in line with previous observations in salivary gland homogenates (Yuda et al. 1996).

The expressional regulation of neuronal NOS is reported to result in different mRNA transcripts (Brenman et al. 1997; Stasiv et al. 2001), which, in turn, may be translated into either functional or non-functional proteins. In addition, NOS enzymatic activity has been shown to be regulated by multiple factors (Alderton et al. 2001). As a consequence, the expression and activity of the enzyme might not always be correlated (Broholm et al. 2003). Our kinetic studies show that a fully active NOS is present in the CNS of $T$. infestans, and that this enzyme shares similar cofactor requirements with other insect NOS (Ribeiro and Nussenzveig 1993; Müller 1994).

\section{Concluding remarks}

Both morphological and biochemical experiments thus support the hypothesis that NO produced by NOS-expressing cells is a ubiquitous messenger molecule in the CNS of $T$. infestans. The location of NOS-LI in the first-order elements of its sensory systems is indicative of the important role of $\mathrm{NO}$ in the first stages of information processing in this species. 


\section{Acknowledgements}

The authors are grateful to D. Canale and A. Stariolo (Center for the Control of Chagas' disease) for providing the insects, to G. Ruffolo and S. Ruffolo for technical assistance, and P. Jansma (Arizona Research Laboratories, Division of Neurobiology, University of Arizona) for expert help with the confocal microscope. The assistance of C. Collmann and M. Kaneko is also acknowledged.

\section{References}

Alderton WK, Cooper CE, Knowles RG. Nitric oxide synthases: structure, function and inhibition. Biochem J 2001;357:593-615. [PubMed: 11463332]

Bicker G. Sources and targets of nitric oxide signalling in insect nervous systems. Cell Tissue Res 2001;303:137-146. [PubMed: 11291761]

Bicker G, Hähnlein I. NADPH-diaphorase expression in neurones and glial cells of the locust brain. Neuroreport 1995;6:325-328. [PubMed: 7538810]

Bicker G, Schmachtenberg O. Cytochemical evidence for nitric oxide/cyclic GMP signal transmission in the visual system of the locust. Eur J Neurosc 1997;9:189-193.

Bradford MM. A rapid and sensitive method for the quantitation of microgram quantities of protein utilizing the principle of protein-dye binding. Anal Biochem 1976;72:248-254. [PubMed: 942051]

Braman RS, Hendrix SA. Nanogram nitrite and nitrate determination in environmental and biological materials by vanadium (III) reduction with chemiluminescence detection. Anal Chem 1989;61:27152718. [PubMed: 2619057]

Brenman JE, Xia H, Chao DS, Black SM, Bredt DS. Regulation of neuronal nitric oxide synthase through alternative transcripts. Dev Neurosci 1997;19:224-231. [PubMed: 9208206]

Broholm H, Rubin I, Kruse A, Braedenstrup O, Schmidt K, Skriver EB, Lauritzen M. Nitric oxide synthase expression and enzymatic activity in human brain tumors. Clin Neuropathol 2003;22:273281. [PubMed: 14672505]

Davies SA. Nitric oxide signalling in insects. Insect Biochem Mol Biol 2000;30:1123-1138. [PubMed: 11044659]

Di Luciano V. Morphology of the stridulatory groove of Triatoma infestans (Hemiptera: Reduviidae). J Med Entomol 1981;18:24-32.

Elphick MR, Jones IW. Localization of soluble guanylyl cyclase $\alpha$-subunit in identified insect neurons. Brain Res 1998;800:170-174. [PubMed: 9685629]

Elphick MR, Rayne RC, Riveros-Moreno V, Moncada S, O'Shea M. Nitric oxide synthesis in locust olfactory interneurons. J Exp Biol 1995;198:821-829. [PubMed: 9318598]

Elphick MR, Williams L, O'Shea M. New features of the locust optic lobe: evidence of a role for nitric oxide in insect vision. J Exp Biol 1996;199:2395-2407. [PubMed: 9320317]

Feelisch M, Noack E. Nitric oxide (NO) formation from nitrovasodilators occurs independently of hemoglobin or non-heme iron. Eur J Pharmacol 1987;142:465-469. [PubMed: 3123257]

Gibson NJ, Nighorn A. Expression of nitric oxide synthase and soluble guanylyl cyclase in the developing olfactory system of Manduca sexta. J Comp Neurol 2000;422:197-205.

Guerenstein PG, Guerin PM. Olfactory and behavioural responses of the blood-sucking bug Triatoma infestans to odours of vertebrate hosts. J Exp Biol 2001;204:585-597. [PubMed: 11171309]

Hsu SM, Raind O, Fanger H. Use of avidin biotin peroxidase complex (ABC) in immunoperoxidase technique. A comparison between $\mathrm{ABC}$ and unlabelled antibody (PAP) procedures. J Histochem Cytochem 1981;29:577-580. [PubMed: 6166661]

Imamura M, Yang J, Yamakawa M. cDNA cloning, characterization and gene expression of nitric oxide synthase from the silkworm, Bombyx mori. Insect Mol Biol 2002;11:257-265. [PubMed: 12000645]

Insausti TC. Nervous system of Triatoma infestans. J Morphol 1994;321:1-17.

Insausti TC, Lazzari CR. The central projection of cephalic mechanosensory axons in the haematophagous bug Triatoma infestans. Mem Inst Oswaldo Cruz 2000;95:381-388. [PubMed: 10800197]

Kurylas AE, Ott SR, Schachtner J, Elphick MR, Williams L, Homberg U. Localization of nitric oxide synthase in the central complex and surrounding midbrain neuropils of the locust Schistocerca gregaria. J Comp Neurol 2005;484:206-223. [PubMed: 15736229] 
Laemmli UK. Cleavage of structural proteins during the assembly of the head of the bacteriophage T4. Nature 1970;227:680-685. [PubMed: 5432063]

Luckhart S, Rosenberg R. Gene structure and polymorphism of an invertebrate nitric oxide synthase gene. Gene 1999;232:25-34. [PubMed: 10333518]

Manrique G, Lazzari CR. Sexual behaviour and stridulation during mating in Triatoma infestans (Hemiptera: Reduviidae). Mem Inst Oswaldo Cruz 1994;89:629-633. [PubMed: 8524065]

Müller U. $\mathrm{Ca}^{2+} /$ calmodulinin dependent nitric oxide synthase in Apis mellifera and Drosophila melanogaster. Eur J Neurosc 1994;6:1362-1370.

Müller U. The nitric oxide system in insects. Prog Neurobiol 1997;51:363-381. [PubMed: 9089793]

Nighorn A, Gibson NJ, Rivers DM, Hildebrand JG, Morton DB. The nitric oxide-cGMP pathway may mediate communication between sensory afferents and projection neurons in the antennal lobe of Manduca sexta. J Neurosci 1998;18:7244-7255. [PubMed: 9736646]

Ott SR, Burrows M. Nitric oxide synthase in the thoracic ganglia of the locust: distribution in the neuropils and morphology of neurones. J Comp Neurol 1998;305:217-230. [PubMed: 9603374]

Regulski M, Tully T. Molecular and biochemical characterization of dNOS: a Drosophila $\mathrm{Ca}^{2+} /$ calmodulin-dependent nitric oxide synthase. Proc Natl Acad Sci USA 1995;92:9072-9076. [PubMed: 7568075]

Reisenman CE, Insausti TC, Lazzari CR. Light-induced and circadian changes in the compound eye of the haematophagous bug Triatoma infestans (Hemiptera: Reduviidae). J Exp Biol 2002;225:201210. [PubMed: 11821486]

Ribeiro JMC, Nussenzveig RH. Nitric oxide synthase activity from a hematophagous insect salivary gland. FEBS Lett 1993;330:165-168. [PubMed: 7689981]

Seidel C, Bicker G. Colocalization of NADPH-diaphorase and GABA-immunoreactivity in the locust olfactory and visual system. Brain Res 1997;769:273-280. [PubMed: 9374195]

Settembrini BP. Circadian rhythms of locomotor activity in Triatoma infestans (Hemiptera: Reduviidae). J Med Entomol 1984;21:204-212. [PubMed: 6374148]

Settembrini BP, Villar MJ. Proctolin in the brain and ganglia of Triatoma infestans. J Morphol 1999;240:39-47.

Settembrini BP, Villar MJ. Distribution of serotonin in the central nervous system of the blood feeding heteropteran, Triatoma infestans (Heteroptera: Reduviidae). J Morphol 2004;260:21-31. [PubMed: 15052594]

Settembrini, BP.; Coronel, MF.; Nowicki, S.; De Pasquale, D.; Villar, MJ. Distribución y caracterización de la sintetasa del óxido nítrico en el sistema nervioso central de. Triatoma infestans; Resúmenes del VI Congreso Argentino de Entomología; San Miguel de Tucumán. 2005. p. 316

Shah S, Hyde DR. Two Drosophila genes that encode the $\alpha$-and $\beta$-subunits of the brain soluble guanylyl cyclase. J Biol Chem 1995;270:15368-15376. [PubMed: 7797526]

Shu S, Ju G, Fan I. The glucose oxidase method in peroxidase histochemistry of the nervous system. Neurosci Lett 1988;85:169-171. [PubMed: 3374833]

Stasiv Y, Regulski M, Kuzin B, Tully T, Enikolopov G. The Drosophila nitric-oxide synthase gene (dNOS) encodes a family of proteins that can modulate NOS activity by acting as dominant negative regulators. J Biol Chem 2001;276:42241-42251. [PubMed: 11526108]

Stürmer K, Bauman O, Walz B. Actin-dependent light induced translocation of mitochondria and ER cisternae in the photoreceptor cells of the locust Schistocerca gregaria. J Cell Sci 1995;108:22732283. [PubMed: 7673347]

Taneja J, Guerrin PM. Oriented responses of the triatomine bugs Rhodnius prolixus and Triatoma infestans to vertebrate odours on a servosphere. J Comp Physiol 1995;176:455-464.[A]

Villar MJ, Settembrini BP, Hökfelt T, Tramezzani JH. NOS is present in the brain of Triatoma infestans and is colocalyzed with CCK. Neuroreport 1994;6:81-84. [PubMed: 7535578]

Wenzel B, Kunst M, Günther C, Ganter GK, Lakes-Harlan R, Elsner N, Heinrich R. Nitric oxide/cyclic guanosine mono-phosphate signaling in the central complex of the grasshopper brain inhibits singing behavior. J Comp Neurol 2005;488:129-139. [PubMed: 15924338]

WHO. TDR Strategic Direction: Chagas' disease. WHO; Geneva: 2002. Special program for research and training in tropical diseases report. 
Yuda M, Hirai M, Miura K, Matsumara H, Ando K, Chinzei Y. CDNA cloning, expression and characterization of nitric-oxide synthase from the salivary glands of the blood-sucking insect Rhodnius prolixus. Eur J Biochem 1996;242:807-812. [PubMed: 9022713] 


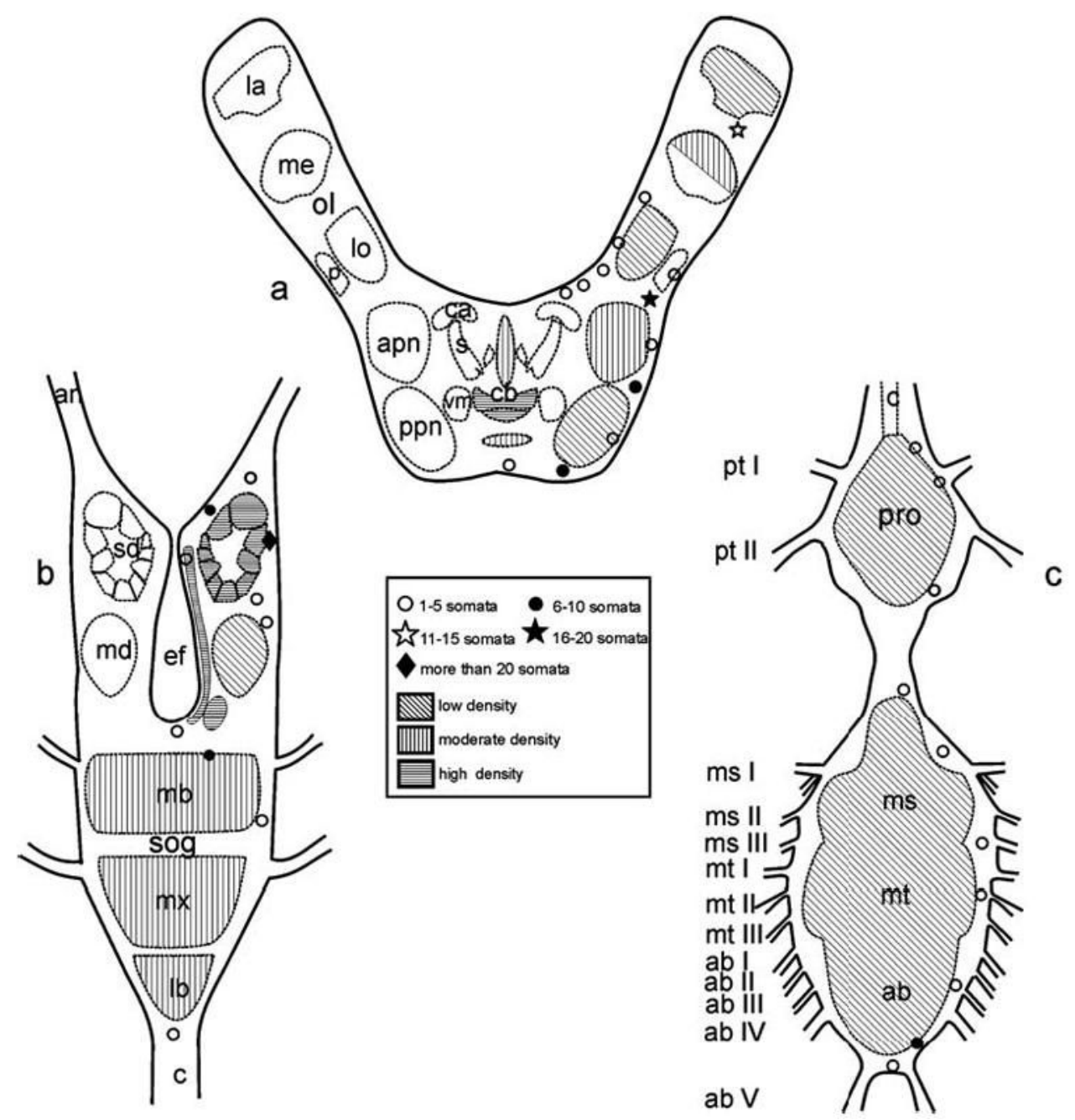

Fig. 1.

Representations of dorsal views of the protocerebrum with optic lobes (a), deutocerebrum (upper part of b), subesophageal ganglion (lower part of b), and thoracic ganglia (c) showing NOS-like immunoreactivity (NO-LI) in Triatoma infestans (symbols number of immunoreactive somata, shadowing density of immunolabeled processes in neuropils, $a b I$ $V$ abdominal nerves I-V, an antennal nerve, apn anterolateral protocerebral neuropil, ca calyx of mushroom body, $c$ connectives, $c b$ central body, ef esophageal foramen, la lamina ganglionaris, lo lobula complex, $m d$ mechanosensory and motor deutocerebrum, $m b-m x-l b$ mandibular, maxillary, and labial neuromeres of the subesophageal ganglion, $m e$ medulla, $m s$ I-III mesothoracic nerves I-III, $m t$ I-III metathoracic nerves I-III, $m s-m t$ - $a b$ mesothoracic, metathoracic, and abdominal neuromeres of the posterior ganglion, ol optic lobe, $p$ lobula plate, ppn posterolateral protocerebral neuropil, pro prothoracic ganglion, pt I-II prothoracic nerves I-II, $s d$ sensory deutocerebral glomeruli, $s o g$ subesophageal ganglion, $s$ stalk, $v m$ lateromedial protocerebral neuropil). Anterior (top) 

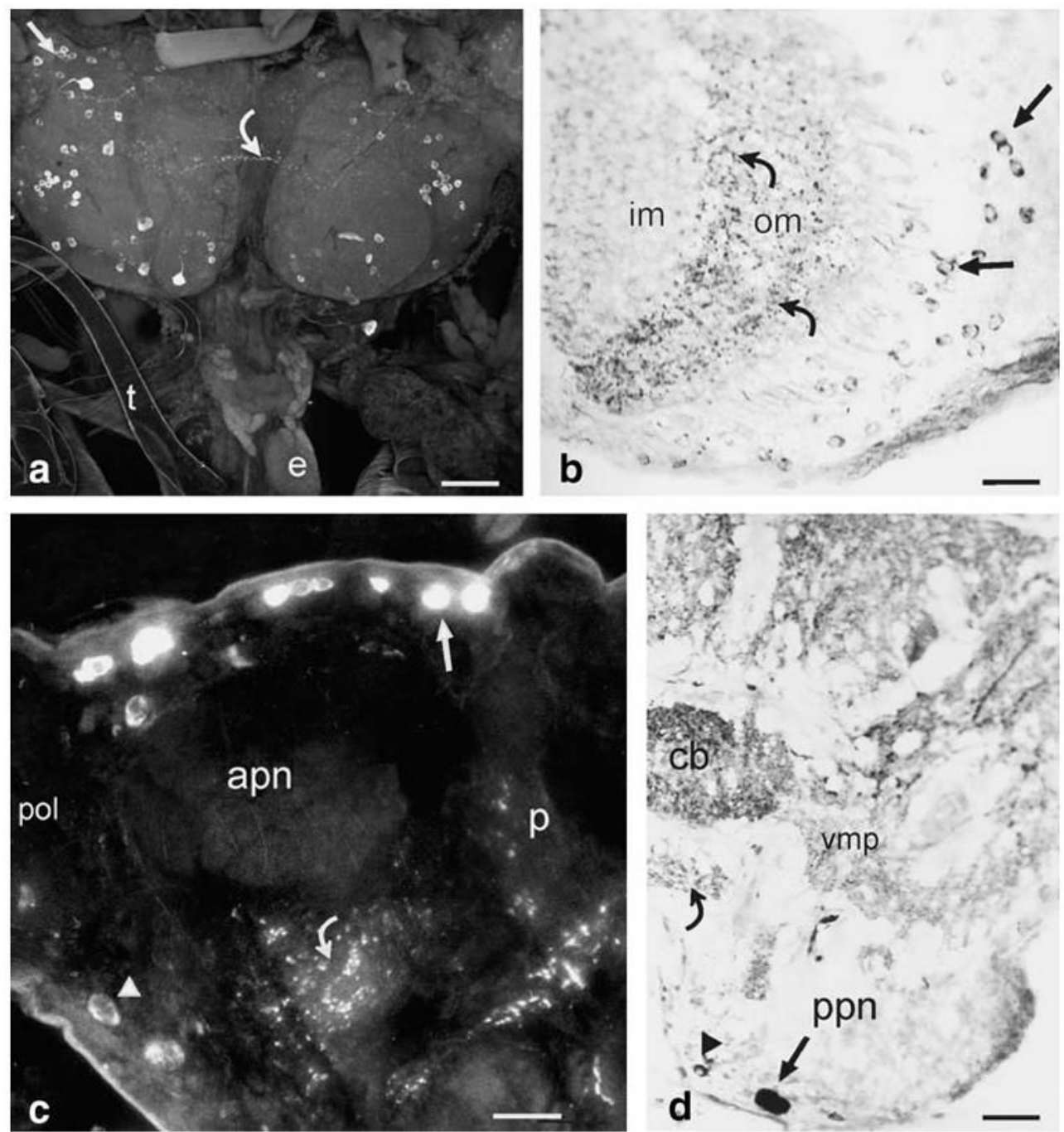

Fig. 2.

Immunofluorescence (a, $\mathbf{c})$ and bright-field $(\mathbf{b}, \mathbf{d})$ micrographs of the protocerebrum and optic lobe. a Confocal image of the protocerebral lobes showing NOS-immunoreactive (IR) perikarya (straight arrow cell bodies at the anterolateral soma rind, curved arrow immunostained neurites crossing the median furrow, $e$ esophagus, $t$ trachea). b Immunostained somata (straight arrows) between the medulla (im inner medulla, om outer medulla) and lamina ganglionaris; note the immunoreactive neurites (curved arrows) in the outer medulla (om). c Immunostained perikarya in the anterior (straight arrow) and lateral (arrowhead) soma rinds; note that the stalk $(p)$ of the mushroom body is mostly unstained (curved arrow positive neurites of the protocerebral neuropil, apn anterolateral protocerebral neuropil, pol proximal optic lobe, $p$ stalk). $\mathbf{d}$ Immunoreactive neurites in the central body $(\mathrm{cb})$, lateromedial neuropil ( $\mathrm{vmp}$ ), and posterior protocerebral commisure (curved arrow; ppn posterolateral protocerebral neuropil). Note the immunopositive cell bodies in the posterior soma rind (arrow, arrowhead). Anterior (top). Bars $100 \mu \mathrm{m}(\mathbf{a}), 20 \mu \mathrm{m}(\mathbf{b}-\mathbf{d})$ 

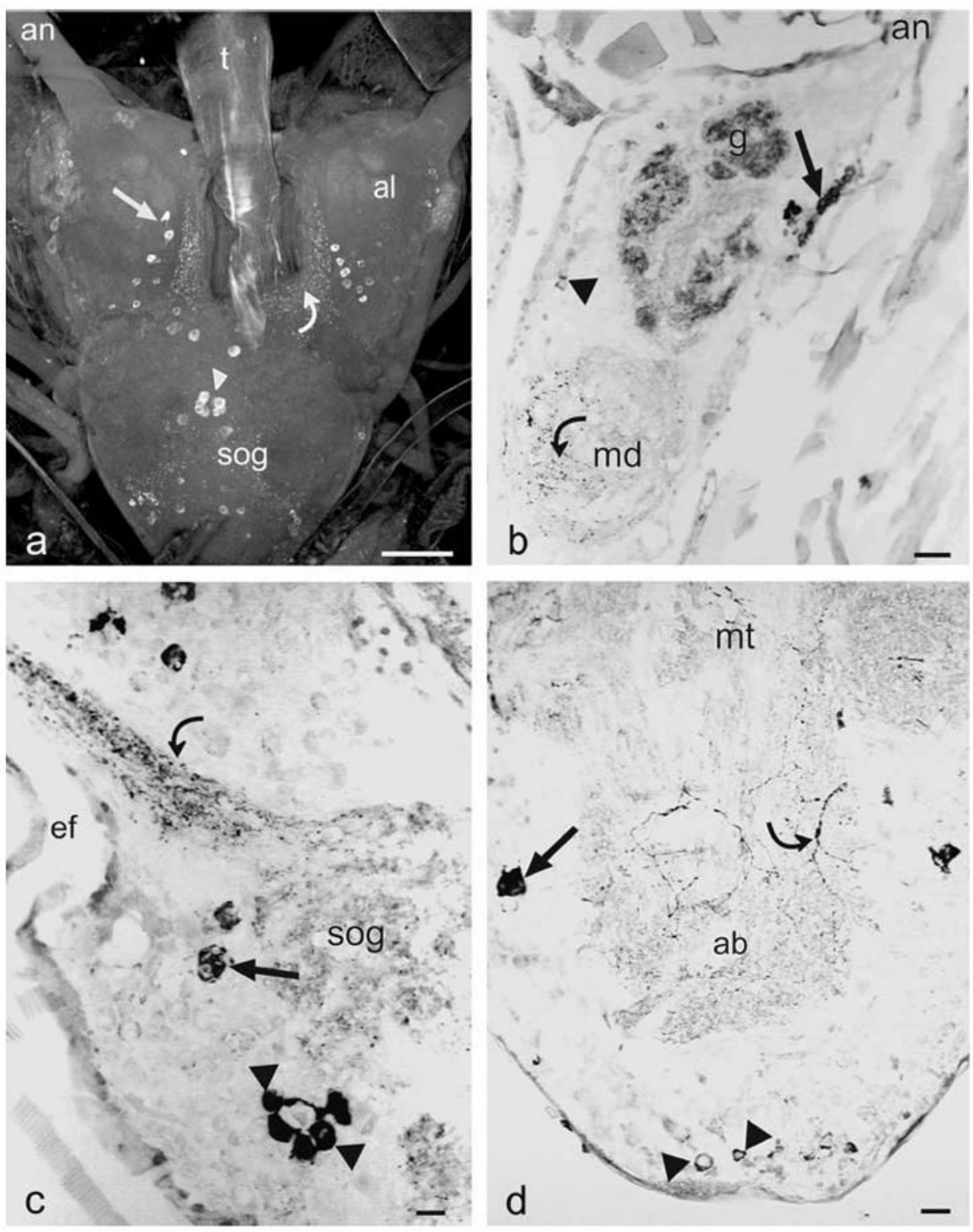

Fig. 3.

NOS-LI in the deutocerebrum $(\mathbf{a}, \mathbf{b})$, the subesophageal ganglion $(\mathbf{c})$, and the posterior ganglion (d). a Confocal immunofluoresce micrograph (an antenal nerve, $t$ trachea) showing stained somata (straight arrow) of the sensory deutocerebrum (al); note the medial cluster of NOS-IR perikarya (arrowhead) in the subesophageal ganglion ( $\operatorname{sog}$ ) and the positive neurites around the esophageal foramen (curved arrow). b Bright-field micrograph (an antennal nerve) showing positive neurites in the sensory $(g)$ and mechanosensory and motor deutocerebrum ( $m d$, curved arrow); note the immunoreactive cell bodies of the lateral cortex (straight arrow) and the cell body in the medial soma layer (arrowhead). c Bright-field micrograph of the subesophageal ganglion (sog); note the cluster of five positive somata (arrowheads) and stained processes (curved arrow) around the esophageal foramen (ef). Other immunostained somata of the subesophageal ganglion are also visible (straight arrow). d Metathoracic $(m t)$ and abdominal neuromeres $(a b)$ of the posterior ganglion (straight arrow bilateral perikarya, 
arrowheads posteromedial cell bodies); note the varicose fibers in abdominal neuromeres (curved arrow). Anterior (top). Bars $100 \mu \mathrm{m}$ (a), $50 \mu \mathrm{m}$ (b), $20 \mu \mathrm{m}$ (c, d) 


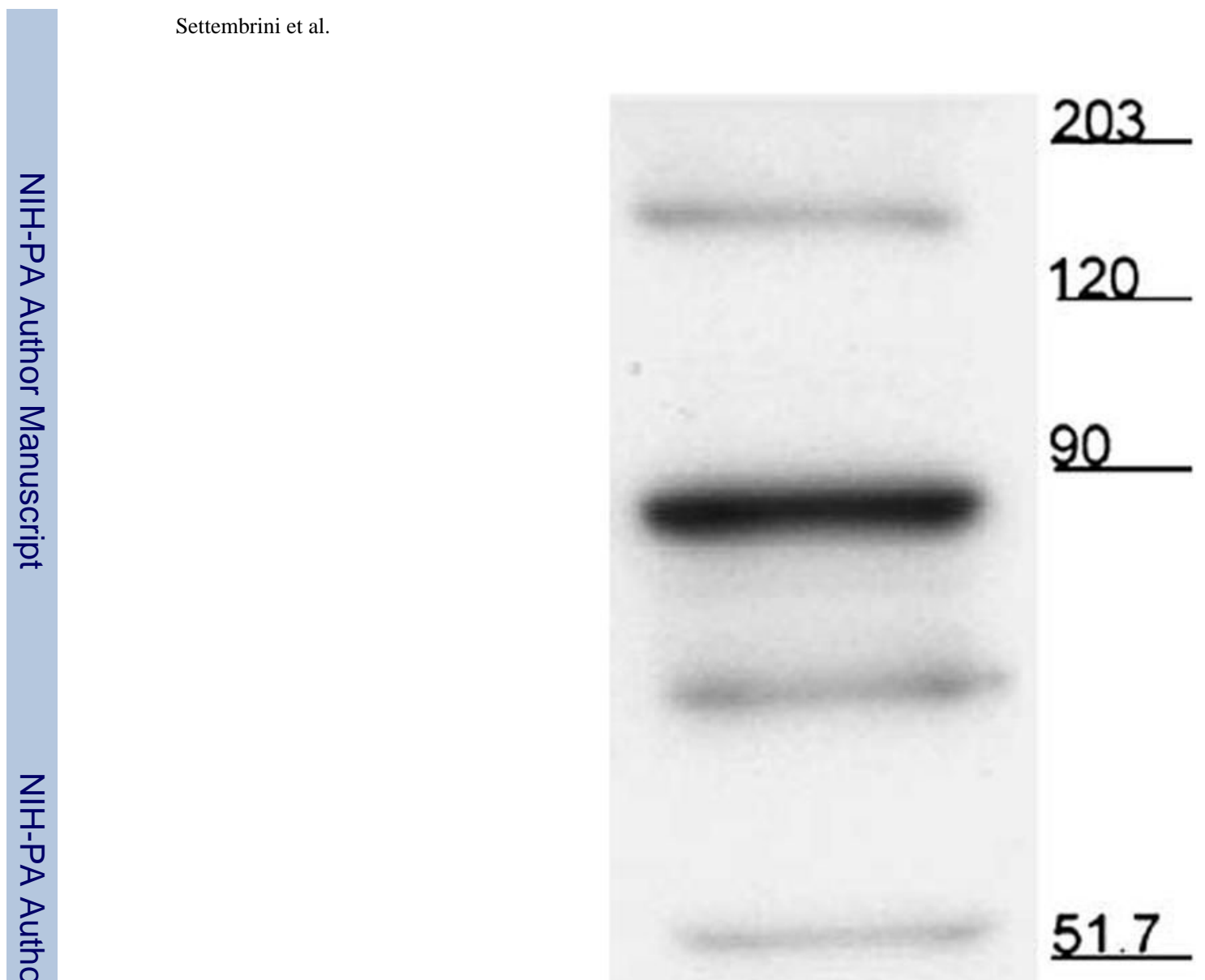

Fig. 4.

Western blotting for uNOS. An immunoreactive band corresponding to the expected molecular mass of NOS was detected at $134 \mathrm{kDa}$. Other bands were present at 90 and $77 \mathrm{kDa}$ 


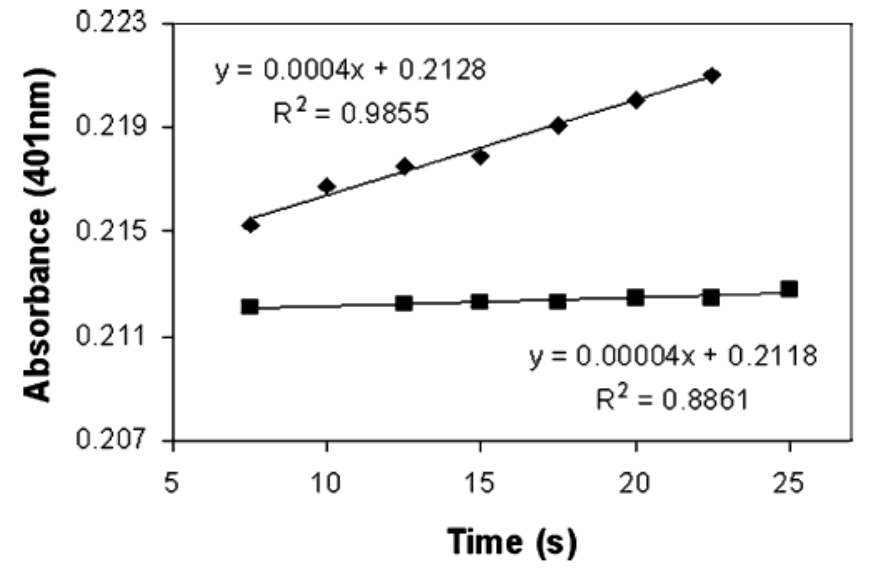

Fig. 5.

Kinetics of the changes in absorbance at $410 \mathrm{~nm}$ attributable to NO production by homogenates of the brain and ganglia of T. infestans in the absence (diamonds) or presence (squares) of 1 mM L-NMMA 